\title{
Exploring the membrane potential of a simple dual membrane system by using a constant electric field
}

\author{
Yerko Escalona*, Jose A Garate, Tomas Perez-Acle \\ From Latin American Student Council Symposium 2014 (LA-SCS 2014) \\ Belo Horizonte, Brazil. 27 October 2014
}

\section{Background}

Connexins (Cxs) constitute Gap Junction Channels (GJCs). GJCs connect the cytoplasm of adjacent cells providing a hydrophilic path between cells that allow the movement, by passive diffusion, of water, cations and small molecules. The opening or closing of GJCs is dependent on the voltage difference between the apposed cells and/or the membrane potential. An approach to understand the voltage gating mechanisms of GJCs is to study a simplified system that can account for the basic features of a GJC.

\section{Results}

In this work, we have devised a series of simple systems bearing in mind that idea. The systems here presented are: i) a dual membrane, ii) a dual membrane with a pore on each membrane, iii) a dual membrane with a channel connecting both membranes and iv) a dual membrane with a channel having explicit charges inside.

In all cases, membrane and pore were built solely with carbon atoms. Both equilibrium and non-equilibrium MD simulations were performed in all systems. Nonequilibrium simulations were produced by applying a uniform external electric field in order to produce a potential difference across the membranes. We then performed detailed analyses of the electrostatic potential, ionic current and the potential of mean force of an ion through the system pores.

\section{Conclusions}

This study provided important insights regarding the behavior of the electrostatic potential and ion currents inside simple dual membrane systems with or without a

\footnotetext{
*Correspondence: yescalona@ug.uchile.cl

Laboratorio de Biología Computacional (DLab), Fundación Ciencia \& Vida,
} Chile and take full advantage of:

- Convenient online submission

- Thorough peer review

- No space constraints or color figure charges

- Immediate publication on acceptance

- Research which is freely available for redistribution
- Inclusion in PubMed, CAS, Scopus and Google Scholar 